\title{
Academic Service-Learning In An Accounting Information Systems Capstone Course
}

\author{
Zafar Khan, Ph.D., CMA, CIA (Email: Zafar.Khan@Emich.edu), Eastern Michigan University
}

Michele M. Haroon (Email: mumtazmh @ hotmail.com), KPMG

\begin{abstract}
This paper presents the use of nonprofit organizations in an Accounting Information System (AIS) capstone course to promote Academic Service Learning (ASL). ASL integrates community service with course requirements, objectives, and outcomes. Use of a carefully planned field project is an ideal approach to realize these dual objectives of providing meaningful community service with academic learning. Conclusions drawn from the use of ASL in the capstone course over the last two years are presented.
\end{abstract}

\section{Introduction}

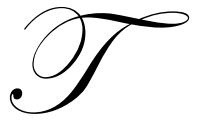

his paper presents the use of nonprofit organizations in an Accounting Information System (AIS) required capstone course over the last two years to promote Academic Service Learning (ASL). The paper begins with a definition of ASL followed by an introduction to the use of ASL in accounting and AIS programs, benefits to students, benefits to universities, and benefits to the organization. Next, a rationale for incorporating ASL in AIS capstone course is provided followed by details of institutional support and selected ASL field projects. The paper concludes with a summary and recommendations for future involvement.

Eastern Michigan University's Office of Academic Service-learning provides the following definition of ASL: "a teaching methodology that utilizes community service as a means of helping students gain a deeper understanding of course objectives, acquire new knowledge, and engage in civic activity." ASL is significantly different from the community service requirements widely used in high schools and colleges across the nation. ASL seeks to integrate community service with individual course requirements, objectives, and outcomes. This is achieved through teaching methodologies such as experiential learning, field experiences, clinical experiences, and field projects. The required capstone course in the AIS program has several objectives including, developing expertise in the design and implementation phases of information systems, and providing experience in implementing control systems. Use of a carefully planned field project at a nonprofit organization is an ideal approach to realize these dual objectives of providing meaningful community service with academic learning.

While utilization of ASL has become commonplace in certain academic disciplines like biology, social work, communication, and the humanities in general, its use in business has been somewhat limited. Other than the well-known VITA (Volunteer Income Tax Assistance), until recently, accounting curricula using ASL was rare though growing. Use of ASL has recently been suggested as a remedy for the shortage of accounting majors. "Stressing the good that accountants do for society would help alleviate the decline in the quantity and quality of accounting majors." students need reassurance that accounting can still be a rewarding and respected career path.

ASL, in academia and in the corporate world, has proved itself invaluable in many ways to many individuals and organizations. Indeed, presently more than half a million students, in over 600 institutions, are involved in ASL projects (Gujarathi and McQuade, 2002). Further, over 300 college and university presidents have signed the

Readers with comments or questions are encouraged to contact the authors via email. 
Declaration on the Civic Responsibility of Higher Education that calls for "higher education to become engaged, through actions and teaching, with its communities." ${ }^{3}$ The AIS program at Eastern Michigan University (EMU) has been successfully using ASL for the last two years.

\section{Benefits to Students}

What makes academic service-learning such a great experience for students? First and foremost, nonprofit social service organizations have a flattened hierarchy since many are under-staffed. These organizations may have large social missions but lack the manpower to fulfill them. This creates wonderful opportunities for students. Whereas they might feel "over-managed" and limited in their capabilities at a business, in the nonprofit world they often are expected to exhibit the "pitch in" mentality common to many organizations that rely heavily on volunteers. These situations are often very empowering and exhilarating for students (Rehling, 2000). Further, our experience shows that nonprofit staff, generally not having studied business, usually trust the students' business/accounting expertise and give students the option to take on as many responsibilities and projects as they want to. In turn, students often become more confident in their abilities and energized as well. The phenomenon of limitless opportunities to contribute talent is the forerunner to all the other numerous benefits to students. ${ }^{4}$

One such benefit to students involved with ASL is the opportunity to develop excellent communication and presentation skills, skills that are vital in both public and managerial accounting (Tucker and McCarthy, 2001). Also, students have the opportunity to get inside very small for-profit businesses and non-profits and perform consulting tasks; these areas would be inaccessible to many students otherwise. In fact, many students have the chance to do information technology consulting. By helping nonprofits embrace technology, students really improve their communication, problem-solving, and analytical skills and become more attractive to recruiters. ${ }^{5}$

In addition, accounting information students gain a tremendous amount of knowledge about the inner workings of a "real" accounting system and discover that the problems people face are much more complex and often less clear than the textbook problems. It provides engaging cases for discussion as well; students often have the opportunity to discuss ethics, cost issues, and internal control issues that arise in many small operations.

Aside from all of the learning opportunities available in ASL, many business students realize that ASL makes them more visible at school and in the community. The most ambitious students understand that, while they may be performing minor tasks for a nonprofit, they are actually forging career paths as leaders, partners of CPA firms, CEOs, CFOs, and so on. Community service demonstrates leadership abilities; it entails taking on responsibility in the public interest, instead of merely going through the motions of reading, doing homework, etc. This aspect of ASL makes it more attractive as well, since volunteerism is often a very attractive vehicle for advancing upwards in a company. Leadership skills developed here can help students/employees gain the "attention of higherups without looking overly ambitious..."6

Perhaps most important, especially in these perilous times, ASL fosters a sense of social and community responsibility in students. The outcome of their work is often very important and engaging. ASL projects improve students' sense of "self-efficacy - beliefs in one's capabilities to organize and execute the courses of action required to produce given attainments." "The value of this is clear. As one student said of a service learning experience, "This kind of work elicits more commitment, because the consequences are real and important to me." Interestingly, some students also feel that community internship experience looks particularly positive on resumes, showing good citizenship and the ability to make a difference (Rehling, 2000).

\section{Benefits to Universities}

Why should educators care about community service in accounting courses? If accounting educators want to change the general stereotype of accountants as bean counters they not only need to train graduates to achieve their personal and professional goals but also to contribute to society. Accounting educators need to contribute to the advancement of the community and convey the importance of corporate citizenship to students--the future corporate leaders. Moreover, ASL assignments not only meet identified community needs, they also make students reflect on the service activity to gain a further understanding of course content, a broader appreciation of the discipline, and an enhanced sense of civic responsibility (Gujarathi and McQuade, 2002). 
The outcomes above place universities in a more strategic position within the community. It is sometimes difficult to vie for the attention of area businesses that may support students and programs through internships, grants, scholarship support, guest speakers and so on. Many faculty have been unsuccessful and frustrated by longstanding organizational policies and priorities but students working with nonprofits often have access to the corporate professionals that sit on boards of directors, for example, and can create opportunities for themselves and their colleges (Rehling, 2000).

By implementing ASL, universities are able to provide a more thorough education to their students. ASL allows educators to provide training that cannot be reproduced in the classroom. This helps build a college's reputation for high quality education. Our experience echoes that of Gujarathi and McQuade (2002) and Rehling (2000) in that the feedback from students has been generally very positive. Most students find that the opportunity to apply course concepts to a real-life situation is very beneficial. A few also realized that their technical skills were very valuable to the community organizations and mentioned that the ASL assignment "helped them grow as a person."

\section{Benefits to Organizations}

One of the major problems that students mention is the difficulty of meeting and getting information and feedback from the busy managers of the sponsoring nonprofit organizations. Nonetheless most complete the projects and are grateful for their managers' time. The managers on their part, in the final evaluation, praise the students' efforts and perseverance and many express gratitude for completion of valuable projects that would otherwise have remained incomplete or cost them much scarce resources. ${ }^{10}$

In addition to simply having free help in these under-staffed organizations, nonprofits that participate in ASL with accounting information systems students learn how to improve their own accounting and/or IT environments. Specifically, nonprofits and their boards can be alerted to internal control deficiencies, for example. Since developing experience in evaluating and implementing internal controls is an important objective, such focus is beneficial to nonprofits, where cases of fraud and embezzlement are increasingly common. ${ }^{11}$ Since so many nonprofits are under-staffed, segregation of duties is often overlooked. By bringing in future accountants, nonprofits can be informed of these deficiencies, and, together with the students and their professors, can find ways to improve them.

Especially critical to many nonprofits is the issue of using technology. Much of nonprofits' staff is untrained in information technology but try, often unsuccessfully, to use it. In today's database and networked world, a lack of technological expertise in an organization can be a substantial handicap. Accounting information systems students, with their technical knowledge of databases and systems, can work in concert with their professors to give nonprofits high quality consulting. This often results in better costing of products/services and more accurate tracking of donors and donations, among other improvements.

Organizations may also enhance their public images within the community through their association with a university. By appearing "pro-education" they can widen their visibility and possibly, their fundraising base as well. Indeed, it may be that, once students have attained their degrees and achieved success in their careers, they will remember the nonprofit and staff who helped him/her and donate money or time. In addition, if an ASL assignment is successful at an organization, the organization's goodwill may be improved in that regard and the university may assign other students to do some different ASL project there, and so on.

\section{Future of ASL in AIS}

The use of academic service learning in accounting information systems curricula promises to increase. Michenzi (1998) and Lenk (1998) also discuss implementation of ASL in their AIS courses. ${ }^{12}$ As indicated above, there is a need for returning goodwill and respectability to the accounting discipline so that the quality and quantity of accounting majors increases. Recently, EMU, like many other educational institutions, has embraced strategies for renewing its engagement with communities, and preparing students for citizenship in a diverse democracy. Accounting educators should utilize ASL as a way to provide students with real-life experiences, develop their core competencies, and also contribute to community and society development. It will also help accounting educators respond to the criticism that accounting is presented as a people-less field (Gujarathi and McQuade, 2002). 


\section{Academic Service Learning at Eastern Michigan University}

The Office of Academic Service-Learning (ASL) at EMU is known nationally for promoting ASL in universities, colleges, and schools. It maintains a highly useful website at http://www.asl.emich.edu/index.html. The Office of ASL acts as a clearinghouse of resources, information, and useful links to students, faculty and community members about ASL at EMU and about ASL in general. For example, students can visit the website and see which classes offer service-learning opportunities. Classes that involve ASL include Sociology, Philosophy, Social Work, and Education but also unexpected ones like Finance, English, Business Technology, and Accounting Information Systems.

The office of ASL organizes and facilitates the further implementation of ASL at EMU. Besides just being a resource for students, the office of ASL website contains links to faculty research/papers, information about grants given to EMU, links to community agencies, and faculty resources. Given the increasing number of print and electronic resources available and strategic emphasis by universities, we should see more and more accounting educators and in particular AIS instructors incorporating ASL in their courses.

\section{Administration of Projects in the Accounting Information Systems Capstone Course}

Having a centralized office of ASL is probably ideal for implementing ASL in not only the AIS curriculum but also other programs across the university. Research shows that the presence of a centralized office is associated with greater institutionalization of ASL into the college curriculum (Bringle and Hatcher, 2000). A centralized office can provide technical assistance, logistical support, monetary incentives, and recognition of meritorious academic service learning endeavors (Bringle and Hatcher, 2000). However, even with a centralized office of ASL, implementing ASL in the AIS curriculum requires considerable time, effort, and commitment from faculty. The first thing instructors, interested in implementing ASL with or without a centralized office of ASL, need to do is identify and get to know the service agencies in their local area. They need to build contacts and identify the information systems related needs of the service organizations including their own university. ${ }^{13}$

The required AIS capstone course at EMU typically has about 15 students. One instructor teaches the three credit hour course. However, the instructor does refer students to other computer information system faculty for advanced programming questions or problems and also to other accounting faculty with expertise in governmental accounting. As the curriculum and course is interdisciplinary in nature there is a formal affirmation of support, however, the effectiveness of the support does depend upon the informal relationship of the instructor with other faculty. The instructor's workload is probably not very different from a typical three credit hour AIS course except to the extent that it requires more upfront planning and organization.

Students are generally assigned to a four-student group with no less than three or more than five students per group. As a significant number of students are commuter students, the instructor does provide some freedom to students in forming their own group based on convenience but at the same time reserving the right to make changes and ensuring adequate diversity in terms of skills, work experience, part-time/fulltime, national/foreign, ethnicity, and gender. It is the student team's responsibility to find a sponsor and project; the instructor does, however, provide support as needed and facilitates the process. While ASL projects are encouraged, not all the student groups use ASL projects. Student teams opting for ASL projects are given the contact information and then it is their responsibility to work with the sponsor to define the project.

Each student team is required to submit a formal project proposal that includes a written signed contract between the team members and the project sponsor during the second/third week of class. In addition the student teams submit three written periodic reports that include specific requirements, and a final project report at the end of the semester. The detailed final project report also includes a letter of evaluation from the sponsor. ${ }^{14}$ The instructor monitors the progress of the project through formal interim written reports and several one-on-one meetings with individual teams. Student teams are also required to make informal class presentations of the interim reports and a formal class presentation of the project during final exam week. Students typically spend about 40 hours each on the project with some students spending as little as 30 and a few spending as much as 80 hours. As the team project is the most significant part of the course and requires considerable amount of time from the students about one-half of the class time during the semester is set aside for the student teams to work on the project. ${ }^{15}$ 


\section{ASL in Accounting Information Systems Capstone Course - Project Examples}

As part of EMU's ASL initiative and as a part of creating the best learning situation possible, the accounting department has implemented ASL. It has been used regularly in governmental/nonprofit accounting classes, advanced managerial accounting, and the required Accounting Information System Capstone Class. Below we provide highlights of two (of the several) ASL projects undertaken by students in the AIS capstone course.

\subsection{The Michigan Women's Foundation.}

Michigan Women's Foundation (MWF) is a non-profit organization founded in 1986 by women with expertise in Law, Medicine, Public Service, Labor, and Education. MWF's goal is to promote self-sufficiency and the personal well-being of women, thereby maximizing their contribution to society. It provides financial and other assistance to organizations for women and educates policy makers on women's issues.

Although MWF had invested in specialized accounting software, they were not realizing the expected benefits. A preliminary analysis indicated that there were many problems with the use of the new software. The software was providing reports with questionable numbers, lacked required reports, confounded fund and expense centers, and did not allocate the budget by month. The student group documented the current system, clarified and improved the data entry process, corrected errors in the chart of accounts, redefined funds and centers, and developed necessary reports using cross-tab queries. They also created a user manual and trained the staff in using the system.

Since MWF already had specialized accounting software and an agreement with the vendor, the student group had to coordinate not only with MWF but the specialty software company. This took time, however, and after some persuasion, the vendor agreed to provide a certain number of hours of technical help via telephone at no charge. In working with software supplied by a third party and needing to make modifications suggested by the analysis, the group encountered unexpected liability issues that needed to be discussed and resolved. As the limited MWF personnel also lacked governmental/non-profit accounting knowledge, the student group, in conjunction with a faculty expert, had to educate the MWF staff. This suggests the importance of being flexible and able to adapt the project to emerging needs. students:

Reflection during and upon completion of the project identified the following benefits to MWF and to the

Benefits to $M W F$

- $\quad$ Better understanding of current system.

- Meet internal and external reporting requirements with accurate and timely reports.

- Better resource utilization.

- $\quad$ Lower operating costs.

Benefits to Students

- Work experience in a professional environment, with real-world considerations, deadlines, and complications.

- Better understanding of fund accounting.

- $\quad$ Learned how to deal with non-accounting personnel.

- $\quad$ Knowledge of software from both user and developer perspective.

- $\quad$ Personal growth (self-esteem, confidence, responsibility).

- $\quad$ Career development (work world, skills, competitive advantage).

- $\quad$ Social development (interpersonal skills, diversity, community participation).

- $\quad$ Academic/cognitive (positive learning experience, AIS knowledge and skills). 


\subsection{The Women's Center of America.}

Another student group in the AIS capstone course designed and implemented a donor maintenance program for the Women's Center of America (WCA). The WCA is a local nonprofit that offers personal, financial, and career counseling, as well as education through workshops to women in Washtenaw County, Michigan. WCA's goal is to empower and help women and girls achieve their full potential.

The WCA is a relatively new startup, just over a year old, that is entirely funded by donations and has an all-volunteer staff. The nonprofit tried very hard but with little success to keep track of donors, potential donors and pledges on paper. They also spent a lot of time writing "thank-you" letters to donors. Thus WCA's need for a donor maintenance program that would allow them to effectively and efficiently increase and maintain their donor base was critical. While such donor maintenance programs are available from vendors specializing in nonprofit software, they are expensive and targeted to nonprofits with fairly large budgets. The student group was able to meet WCA's critical need through a customized, inexpensive MS Access based donor maintenance program.

The student group used system analysis methodology to identify user needs and identify relationships between donors, pledges, and donations. The student group analyzed and documented current and proposed businesses processes at the WCA. Finally the student group designed and developed an MS Access database with queries that would allow the generation of the following reports:

- Historical Donor Info by Month - showed all donations with their corresponding information, grouped by month.

- $\quad$ All Mailing Labels - made labels for all of the above donors.

- $\quad$ Pledges outstanding - showed pledges outstanding for six months or more.

- $\quad$ Thank-you letter mailing labels - made mailing labels to people who had donated within the last fourteen days.

- $\quad$ Last year donor report - showed information for donations made during the last year and also last nine months. (This was created to facilitate fundraising during the all-important Christmas season, October through December.)

- Donations over $\$ \mathbf{4 0 0}$ - this showed information on donations that were greater than $\$ 400$. This is significant because it helps the organization identify larger donors. It also helps donors if they need to substantiate these larger donations for tax purposes.

Upon successful design and testing of all of the queries and reports, the group used Access's "hiding" capability to hide queries that were critical to the correct operation of the system so that naïve users could not unintentionally change them. The group also completed a user manual. Once the database was implemented, the student group provided training to the main user of the program. This user, well versed in Microsoft Access, was very pleased with the results. The Executive Director of WCA was also very happy and looked forward to the improved functioning of WCA's fundraising efforts. students:

Reflection during and upon completion of the project identified the following benefits to WCA and to the

\section{Benefits to WCA}

- $\quad$ Effective tracking and reporting of donation transactions.

- $\quad$ Meaningful data \& reports on donors.

- $\quad$ Automatic generation of letters to donors.

- $\quad$ Ability to reduce errors to minimum level.

- Control of donor information.

- $\quad$ Efficiency in fundraising, data entry, reporting functions.

- $\quad$ More effective fundraising capabilities.

- $\quad$ Meaningful data on clients. 


\section{Benefits to Students}

- Work experience in a professional environment, with real-world considerations, deadlines, and complications.

- $\quad$ Success in group endeavor (team bonding-ASL project in other accounting course.)

- $\quad$ More effective client communication abilities.

- $\quad$ Advanced systems design and accounting information system skills.

- Understanding of communication needs in dealing with non-accounting personnel.

- $\quad$ Personal growth (self-esteem, confidence, responsibility.)

- $\quad$ Career development (work world, skills, competitive advantage.)

- $\quad$ Social development (interpersonal skills, diversity, community participation.)

- $\quad$ Academic/cognitive development (positive learning experience, AIS knowledge and skills.)

\section{Conclusion and Suggestions for Future research}

While there may be questions about the appropriateness of ASL in intermediate accounting or accounting theory, the objectives of AIS project implementation courses easily lend themselves to incorporating ASL field projects. Objectives of most AIS project implementation courses are probably not much different from the following:

- $\quad$ To develop expertise in the design and implementation phase of information systems.

- To provide experience in evaluating and/or implementing control systems.

- $\quad$ To foster ability to keep up with the rapid changes in information technologies.

- $\quad$ To present the concept of Total Quality Management (TQM) and Business Process Reengineering (BPR) and their impacts on financial information systems.

- To enhance analytical ability.

- To enhance oral and written presentation skills.

- To develop teamwork capability.

- $\quad$ To engage in research of contemporary issues in AIS area.

- $\quad$ To develop computer applications skills-implement designed system by employing one of the available software.

For reasons mentioned above AIS field projects provide an excellent opportunity to gain ASL experience. ASL helps learn the objectives of the course more effectively. There is a significant opportunity for AIS students to apply both their accounting and information systems knowledge to provide accounting and reporting solutions to nonprofits, particularly the small community based organizations that lack significant resources. We see ASL as a win-win situation for both the nonprofit organizations and AIS students. The nonprofit organizations get affordable help with their accounting and reporting problems and the AIS students get valuable experience with design and implementation of information systems and internal control systems. Applying newly acquired skills and knowledge in real-life situations in their own communities contributes to students' personal growth and sense of civic responsibility. As mentioned above having an office of ASL is an ideal situation. However, implementation of ASL without such an office is also feasible but requires more effort on the part of the instructor.

There is significant evidence both in the literature and our limited experience with ASL that the overall experience of both students and nonprofit sponsor organizations is very positive. Nonprofits offer better access for students then many large businesses. However, like any other field projects, ASL projects also require careful planning and coordination. The key to successful implementation is flexibility-adapt projects and goals without compromising overall course goals and objectives.

A recent survey sponsored by the W.K. Kellogg Foundation found that nine of ten respondents would like service learning programs included in their local schools. They believe service learning offers important lessons in good citizenship. ${ }^{16}$ We believe that ASL has proven to be a vital part of the accounting curricula at EMU and promises to continue doing so in years to come. Rama et al. (2000) provide a comprehensive review of the ASL literature and offer many suggestions for structuring ASL projects and research opportunities. Use of ASL in accounting and AIS is still in its infancy. Current publications are largely, small sample, case based research and anecdotal in nature. However, as implementation of ASL increases, there will be increased opportunities and need for research on 
The Review Of Business Information Systems

Volume 6, Number 4

all aspects. $\mathbb{E D}$ 


\section{Endnotes}

1 See http://www.asl.emich.edu/index.html - Office of Academic Service-Learning, Eastern Michigan University

2 Vangermeersch quoted in Gujarathi, Mahendra R. and Ralph J McQuade. "Service learning: Extending the curriculum."

3 Quoted in Rama, Dasaratha V, et al., "Service-learning outcomes: Guidelines for educators and researchers."

4 For example, students have done multiple ASL projects at the same nonprofit organization for their AIS course and other accounting courses.

5 Three student groups that worked on ASL projects submitted their work for review and upon acceptance made high quality presentations in the Undergraduate Symposium and Graduate Research Fair at Eastern Michigan University. Two such students collaborated with faculty on papers submitted to academic conferences. Further, many students got multiple job offers and several accepted jobs with the "big five".

6 Spaeth, Merrie. "Volunteer visibility."

7 Tucker, Mary L and Anne M McCarthy. "Presentation self-efficacy: Increasing communications skills through service-learning."

8 Quoted in Rehling, Louise. "Doing good while doing well: Service learning internships." Our experience is very similar.

9 While the quote is from Gujarathi, Mahendra R. and Ralph J McQuade, "Service learning: Extending the curriculum," our ASL student participants had similar sentiments.

10 Also see Rehling, Louise. "Doing good while doing well: Service learning internships."

11 See Flesher, Dale L and John B Duncan. "Control in volunteer organizations."

12 See Michenzi, Alfred R. "Service-Learning Project in the Accounting Information Systems Course: Implementation Without the Benefit of Hindsight"; and Lenk, Margarita M. "Reaching Our Goals Together in ServiceLearning: A Multi-Semester Accounting Information Systems Course Implementation."

13 This process while time consuming is really not difficult, unless we are talking about an isolated rural campus. At EMU (located next to a major metropolitan area) we have numerous service agencies in the neighborhood with viable potential ASL information systems projects.

14 Most of the sponsor letters to date have been very laudatory and highly appreciative of the students' work.

15 This also helps minimize team meeting scheduling conflicts for the many students who work 20-40 hours a week.

16 See Anonymous, "Poll reveals strong service-learning support."

\section{References}

1. Anonymous, "Poll reveals strong service-learning support," Nonprofit World, Madison; Jan/Feb 2002.

2. Berry, Leonard, "Generous companies serve the best," Marketing Management, vol. 10, no. 4, November/December 2001, pp. 12-13

3. $\quad$ Briggs, Jimmie, “Geeks on a do-good rampage!” Fortune, vol. 144, no. 1, July 2001, pp.182-189.

4. Bringle, Robert G., and Julie A. Hatche, "Institutionalization of service learning in higher education," The Journal of Higher Education, vol. 71, no. 3, May/June 2000, pp 273-290.

5. Flesher, Dale L and John B Duncan. "Control in volunteer organizations," The Internal Auditor, vol. 56, no. 6, December 1999, pp. 45-47.

6. Gujarathi, Mahendra R. and Ralph J McQuade, "Service learning: Extending the curriculum," The CPA Journal, vol. 72, no. 2, February 2002, pp 657-692.

7. Lenk, Margarita M., "Reaching Our Goals Together in Service-Learning: A Multi-Semester Accounting Information Systems Course Implementation," Learning by Doing: Concepts and Models for ServiceLearning in Accounting, ed. D. V. Rama, American Association for Higher Education, 1998, pp. 147-155.

8. Michenzi, Alfred R., "Service-Learning Project in the Accounting Information Systems Course: Implementation Without the Benefit of Hindsight," Learning by Doing: Concepts and Models for Service-Learning in Accounting, ed. D. V. Rama, American Association for Higher Education, 1998, pp. 133-146.

9. Rama, Dasaratha V, et al., "Service-learning outcomes: Guidelines for educators and researchers," Issues in Accounting Education, vol. 15, no. 4, November 2000, pp. 657-792.

10. Rehling, Louise, "Doing good while doing well: Service learning internships," Business Communication Quarterly, vol. 63, no. 1, March 2000, pp. 77-89.

11. Spaeth, Merrie, "Volunteer visibility," Risk Management, vol. 48, no. 7, July 2001, pp. 108-110

12. Tucker, Mary L and Anne M McCarthy, "Presentation self-efficacy Increasing communications skills through service-learning," Journal of Managerial Issues, vol. 13, no. 2, Summer 2001, pp. 227-244. 


\section{NOTES}

